\title{
A Three-Dimensional Comprehensive Model for Prediction of Macrosegregation in Electroslag Remelting Ingot
}

\author{
Qiang WANG ${ }^{1{ }^{1 *}}$ Fang WANG, ${ }^{1)}$ Baokuan $\mathrm{LI}^{11}$ and Fumitaka TSUKIHASHI ${ }^{21}$ \\ 1) School of Materials and Metallurgy, Northeastern University, Shenyang, Liaoning Province, 110819 China. \\ 2) Department of Advanced Materials Science, Graduate School of Frontier Sciences, The University of Tokyo, 5-1-5, \\ Kashiwanoha, Kashiwa, Chiba, 277-8561 Japan.
}

(Received on December 21, 2014; accepted on February 17, 2015)

\begin{abstract}
A transient three-dimensional (3D) comprehensive model is established to understand the macrosegregation in the electroslag remelting (ESR) process. The electromagnetism, two-phase flow and heat transfer are included. The volume of fluid (VOF) approach is employed to trace the metal droplet. The solidification is modeled by an enthalpy-based technique. The solute transport is analyzed by the continuum mixture model. A reasonable agreement is obtained between the experiment and simulation. The results indicate that the liquid composition in mushy zone becomes enriched in $\mathrm{Ni}$. The interdendritic metal with a higher $\mathrm{Ni}$ is replaced by the $\mathrm{Ni}$ poor metal carried by the downward flow in the pool. The Ni composition accumulates at the pool bottom and the concentration increases with time. The species movement is dominated by the thermal buoyancy because of the forced cooling. A negative segregation in the lower part and a positive segregation in the upper part are formed in the ingot. Thanks to the rapid solidification, the $\mathrm{Ni}$ is immobilized before moving to the other place resulting in a lower segregation level. The segregation becomes severer with the increasing current. The maximal positive and negative segregation indexes increase from 0.02742 to 0.03226 and from -0.01346 to -0.01561 with the current ranging from 1000 A to $2000 \mathrm{~A}$.
\end{abstract}

KEY WORDS: electroslag remelting; macrosegregation; numerical simulation; electromagnetism; heat transfer.

\section{Introduction}

ESR is an advanced technology of ingot production which is used in critical applications such as aeronautics, power generation, medicine, and tooling. ${ }^{1)}$ Figure 1 shows the schematic of the ESR process. The passage of an alternating current $(\mathrm{AC})$ from the electrode to the baseplate creates a Joule heating in the highly resistive calcium fluoride-based slag, which is sufficient to melt the electrode. The interaction between the self-induced magnetic field and the AC gives rise to the Lorentz force. Metal droplets sink through the less dense slag to form a liquid metal pool in the watercooled mold. Heat loss to the mold solidifies the metal, forming an ingot with dendritic structure and maintaining a shallow liquid metal pool throughout the process. ${ }^{2)}$ However, macrosegregation occurs during the ESR process due to the relative movement of the solute-rich or poor liquid and solid phases. Moreover, the segregation levels become larger as ingot diameter increases. ${ }^{3)}$

In order to reduce the macrosegregation in the ESR ingots, a deeper understanding of the macroscopic solutal transport should be developed. Given the complicated phenomena involved, and the difficulty and expense of perform-

* Corresponding author: E-mail: wangqdbdx@163.com

DOI: http://dx.doi.org/10.2355/isijinternational.55.1010 ing experiments on a real apparatus, numerical simulations constitute an attractive approach. The macrosegregation in heavy steel ingots are well investigated. ${ }^{4-6)}$ These works indicated that the species movement was dominated by the thermally and solutally driven natural convection of the melt in the mushy zone, flow due to solidification contraction, and the sedimentation of free equiaxed crystals. Due to the forced cooling and electromagnetic fields, the macrosegregation pattern in the ESR ingots significantly changes. ${ }^{7)}$

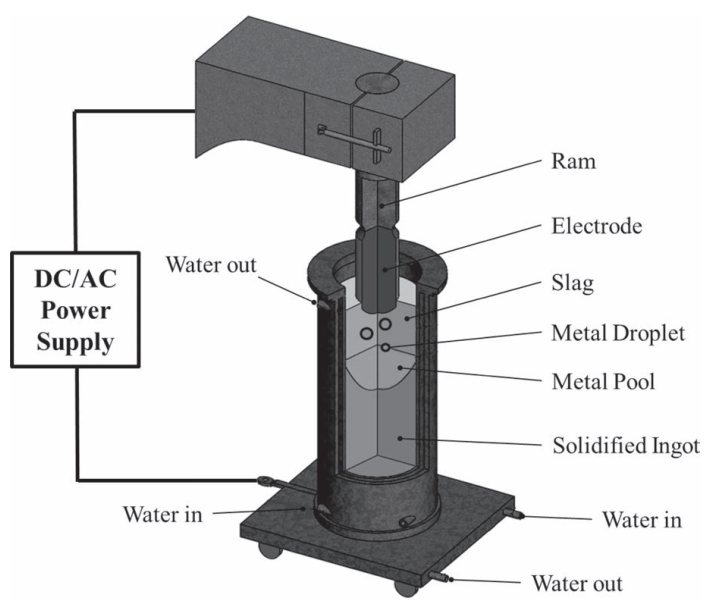

Fig. 1. Schematic of electroslag remelting process. 
Ridder et al. simulated the macrosegregation in the mushy zone of the ESR ingots. The interdendritic heat flow greatly influenced the macrosegregation. ${ }^{8)}$ Fezi et al. numerically investigated the effects of ingot diameter, current and initial composition on the macrosegregation in the ESR process. ${ }^{9}$ ) They hold that processing ingots with a smaller current and an initial composition in the low end of the specification range was the best choice to reduce the macrosegregation. However, the critical part of the process, the electromagnetism, was not included in the works mentioned above. Kelkar et al. developed a two-dimensional coupled model for the analysis of electromagnetics, flow, and heat transfer, as well as the macrosegregation in the ESR process. ${ }^{10)}$ Macrosegregation tended to occur in the metal pool due to the weaker motion. Nevertheless, the metal droplet movement was not considered in their work.

There is currently a lack of general coupled works concerning the macrosegregation in the ESR process. A transient 3D comprehensive mathematical model is developed to analysis the solute transport during the ESR process. The electromagnetism, heat transfer and two-phase flow are included. An experiment is carried out to validate the model. Besides, the effect of the current on compositional fields is demonstrated.

\section{Model Description}

\subsection{Assumptions}

In order to keep the computational time reasonable, the model relies on the following assumptions:

(1) The electrode and mold regions are neglected. The domain includes the slag, the metal pool and the ingot. The immersion depth of the electrode in the slag is ignored. ${ }^{11)}$

(2) The densities of slag and metal are assumed to be dependent on temperature and local solute content. The effect of temperature on the slag electrical conductivity is also included. The other properties of slag and metal are supposed to be constant. ${ }^{12)}$

(3) We assumed that the solidified slag skin electrically insulates the slag and metal from the mold. ${ }^{13}$ )

(4) The solidification shrinkage is neglected. ${ }^{14)}$

(5) Five elements, C, Mn, Cr, Ni and Mo, are included, and others are not taken into account. ${ }^{15)}$

\subsection{Electromagnetism}

The general transport equation for electromagnetic fields is:

$$
\frac{\partial \vec{H}}{\partial t}=\nabla \times(\vec{v} \times \vec{H})+\eta \nabla^{2} \vec{H}
$$

The magnetic Reynolds number, which expresses the ratio of the magnetic convection to magnetic diffusion, remains very low during the ESR process. ${ }^{16)}$ Thus, Eq. (1) is simplified:

$$
\frac{\partial \vec{H}}{\partial t}=\eta \nabla^{2} \vec{H}
$$

Phasor notation is used to account for the periodic time dependence of the magnetic field: ${ }^{17)}$

$$
\vec{H}=\hat{H} e^{j \omega t} \text { with } j^{2}=-1
$$

The complex amplitude $\hat{H}$ is dependent on the position of AC. With Maxwell's equations and appropriate boundary conditions, we obtain the time-averaged Joule heating and Lorentz force.

\subsection{Fluid Flow}

The flow is modeled with the continuity and time-averaged Navier-Stokes equations: ${ }^{18)}$

$$
\begin{array}{r}
\frac{\partial \rho}{\partial t}+\nabla \cdot(\rho \vec{v})=0 \\
{\left[\frac{\partial(\rho \vec{v})}{\partial t}+\nabla \cdot(\rho \vec{v} \times \vec{v})\right]} \\
=-\nabla p+\mu_{e f f} \nabla^{2} \vec{v}+\vec{F}+\vec{F}_{t}+\vec{F}_{s}+\vec{F}_{d}
\end{array}
$$

where $\vec{F}_{t}$ and $\vec{F}_{s}$ are the thermal and solutal buoyancies determined by the Boussinesq approximation. We treat the mushy zone as a porous medium where the porosity gradually decreases from 1 to 0 as the metal solidified. $\vec{F}_{d}$ is the turbulent damping force solved by the Darcy's law. ${ }^{18)}$ The permeability of the mushy zone, described by the KozenyCarman law, is related to secondary dendrite arm spacing. ${ }^{10)}$

The movement of the slag and metal is weakly turbulent. ${ }^{19)}$ The RNG $k-\varepsilon$ turbulence model, which is able to capture the behavior of flows with lower Reynolds number, is employed to calculate the turbulent viscosity. ${ }^{20)}$ An enhanced wall function is employed to work with the RNG $k$ - $\varepsilon$ turbulence model, particularly since liquid metal has a low Prandtl number. The interface between the metal and slag is tracked with the VOF approach. The continuum surface force model is implemented to consider the surface tension.

\subsection{Heat Transfer and Solidification}

The energy conservation equation of the enthalpy-formulation is employed:21)

$$
\frac{\partial}{\partial t}(\rho H)+\nabla \cdot(\rho \vec{v} H)=\nabla \cdot\left(k_{e f f} \nabla T\right)+Q
$$

The enthalpy of the metal and the slag is computed as the sum of the sensible enthalpy and the latent heat released in the mushy zone:22)

$$
H=h+f_{\ell} L \text { and } h=h_{\text {ref }}+\int_{T_{\text {ref }}}^{T} c_{p} d T
$$

The liquidus and solidus temperatures are a function of the local solute concentration: ${ }^{23)}$

$$
T_{\ell}=T_{\text {pure }}+\sum m_{i} c_{i} \text { and } T_{s}=T_{\text {pure }}+\sum m_{i} c_{i} / k_{i}
$$

At the same time, the liquid fraction is updated as:

$$
f_{\ell}^{n+1}=f_{\ell}^{n}-\lambda \frac{a_{p}\left(T-T^{*}\right) \Delta t}{\rho V_{c} L-a_{p} \Delta t L \frac{\partial T^{*}}{\partial f_{\ell}^{n}}}
$$

where the superscript $n$ indicates the iteration number, $\lambda$ is a relaxation factor with a value of $0.9, a_{p}$ is the cell matrix coefficient, $\Delta t$ is the time step, $V_{c}$ is the cell volume, and $T^{*}$ is the liquid/solid interface temperature. The lever rule is used to describe the liquid/solid interface temperature, and the interfacial transfer of species at the liquid/solid interface as well as the species movement in the solid phase. ${ }^{24)}$ 


\subsection{Solute Transport}

Local solute mass fraction is described by the continuum mixture model: ${ }^{4)}$

$$
\begin{aligned}
& \frac{\partial\left(\rho c_{i}\right)}{\partial t}+\nabla \cdot\left(\rho \vec{v} c_{i}\right)= \\
& \nabla \cdot\left[\rho\left(D_{\ell, i}+\frac{\mu_{t}}{S c_{t}}\right) \nabla c_{i}\right]+S_{s, d i f f}+S_{s, c o n}
\end{aligned}
$$

The source terms $S_{s, \text { dif }}$ and $S_{s, c o n}$ express the molecular and convection diffusions:

$$
\begin{aligned}
S_{s, \text { dif }}= & \nabla \cdot\left[\rho f_{s} D_{s, i} \nabla\left(c_{s, i}-c_{i}\right)\right] \\
& +\nabla \cdot\left[\rho f_{\ell}\left(D_{\ell, i}+\frac{\mu_{t}}{S c_{t}}\right) \nabla\left(c_{\ell, i}-c_{i}\right)\right] \ldots \ldots . \\
S_{s, \text { con }} & =\nabla \cdot\left[\rho\left(\vec{v}-\vec{v}_{s}\right)\left(c_{\ell, i}-c_{i}\right)\right] \ldots \ldots \ldots \ldots \ldots
\end{aligned}
$$

\subsection{Boundary Conditions}

The magnetic field intensity continuous at the inlet and bottom, and is related to the current on the top surface of slag and the mold lateral wall: ${ }^{13)}$

Inlet and bottom:

$$
H_{x}=H_{y}=\frac{\partial H_{z}}{\partial z}=0
$$

Top surface of slag and mold lateral wall:

$$
H_{x}=H_{y}=0 \text { and } H_{z}=\frac{I}{2 \pi r}
$$

The melt rates with different currents are obtained from our previous work ${ }^{19)}$ and are imposed at the inlet. The concentrations of the five elements in the metal droplet at the inlet are equal to the nominal content of the AISI 201 stainless steel. A no-slip condition is applied to the lateral wall and bottom. A zero shear stress is adopted on the top surface of the slag. ${ }^{16)}$

In order to consider the melting process in a more simplified way, the temperature of the metal at the inlet is given by a parabolic profile. This parabolic profile has an approximate $30 \mathrm{~K}$ superheat and a peripheral boundary temperature close to the metal liquidus temperature. ${ }^{3)}$ Equivalent heat transfer coefficients are applied to the lateral wall and bottom. ${ }^{22,25)}$ The detailed physical properties are listed in Tables $\mathbf{1}$ and $\mathbf{2}$.

\section{Solution Procedure}

The governing equations have been discretized based on the Finite Volume Method. The domain is divided into a large number of small control volumes, while the variables are determined in each of these control volumes. The metal droplets coming from the inlet contributes to the liquid metal pool. As a result, the ingot grows and the slag layer moves upward. The VOF approach is employed to distinguish the slag and metal, and the dynamic mesh is used to consider the growing. The top row of control volumes spawn a new row of control volumes once they are 1.25 times the height of the other rows. Moreover, the rising velocity is determined by the melt rate of the metal droplet. ${ }^{14)}$ Figure 2 shows the mesh at the initial state. The commercial software ANSYS-
Fluent version 12.1 is employed, because it provides a flexible platform in defining exchange and source terms within equations, including modification of the transport quantities. The governing equations for the electromagnetism, twophase flow, heat transfer, phase change and solute transport

\begin{tabular}{|c|c|c|}
\hline Parameter & Value & Ref. \\
\hline \multicolumn{3}{|l|}{ Physical properties of metal } \\
\hline Density, $\mathrm{kg} / \mathrm{m}^{3}$ & 7500 & 15) \\
\hline Melting point of pure iron, $\mathrm{K}$ & 1805.15 & 4) \\
\hline Dynamic viscosity, $\mathrm{Pa} \cdot \mathrm{s}$ & 0.0061 & 13) \\
\hline Latent heat of fusion, $\mathrm{kJ} / \mathrm{kg}$ & 270 & 13) \\
\hline Thermal conductivity, $\mathrm{W} / \mathrm{m} \cdot \mathrm{K}$ & 30.52 & 13) \\
\hline Specific heat, $\mathrm{J} / \mathrm{kg} \cdot \mathrm{K}$ & 752 & 13) \\
\hline Electrical conductivity, $\Omega^{-1} \cdot \mathrm{m}^{-1}$ & $7.14 \times 10^{5}$ & 13) \\
\hline Magnetic permeability, $\mathrm{H} / \mathrm{m}$ & $1.257 \times 10^{-6}$ & 13) \\
\hline $\begin{array}{l}\text { Thermal coefficient of cubical } \\
\text { expansion, } \mathrm{K}^{-1}\end{array}$ & $1 \times 10^{-3}$ & 13) \\
\hline \multicolumn{3}{|l|}{ Physical properties of slag } \\
\hline Density, $\mathrm{kg} / \mathrm{m}^{3}$ & 2800 & 22) \\
\hline Liquidus temperature, $\mathrm{K}$ & 1650 & 22) \\
\hline Dynamic viscosity, $\mathrm{Pa} \cdot \mathrm{s}$ & 0.0025 & 22) \\
\hline Thermal conductivity, $\mathrm{W} / \mathrm{m} \cdot \mathrm{K}$ & 10.46 & 22) \\
\hline Specific heat, $\mathrm{J} / \mathrm{kg} \cdot \mathrm{K}$ & 1255 & 22) \\
\hline Electrical conductivity, $\Omega^{-1} \cdot \mathrm{m}^{-1}$ & $\ln \sigma=-6769.0 / T+8.818$ & 13) \\
\hline Magnetic permeability, $\mathrm{H} / \mathrm{m}$ & $1.257 \times 10^{-6}$ & 13) \\
\hline $\begin{array}{l}\text { Thermal coefficient of cubical } \\
\text { expansion, } \mathrm{K}^{-1}\end{array}$ & $1 \times 10^{-4}$ & 13) \\
\hline
\end{tabular}
are solved simultaneously, using an iterative procedure. Before advancing, the iterative procedure continues until all normalized unscaled residuals are less than $10^{-6}$. Due to the complexity of the coupling calculation, the time step is kept small to ensure the above convergence criteria are fulfilled.

Table 1. Physical properties of metal and slag.

Table 2. Compositions of the electrode.

\begin{tabular}{ccccccccc}
\hline Species & $\mathrm{C}$ & $\mathrm{Si}$ & $\mathrm{Mn}$ & $\mathrm{Cr}$ & $\mathrm{P}$ & $\mathrm{S}$ & $\mathrm{Ni}$ & $\mathrm{Mo}$ \\
\hline $\begin{array}{c}\text { Nominal } \\
\text { concentration, } \\
\text { wt. } \%\end{array}$ & 0.15 & 0.75 & 2.51 & 24.61 & 0.01 & 0.02 & 4.15 & 2 \\
\hline
\end{tabular}

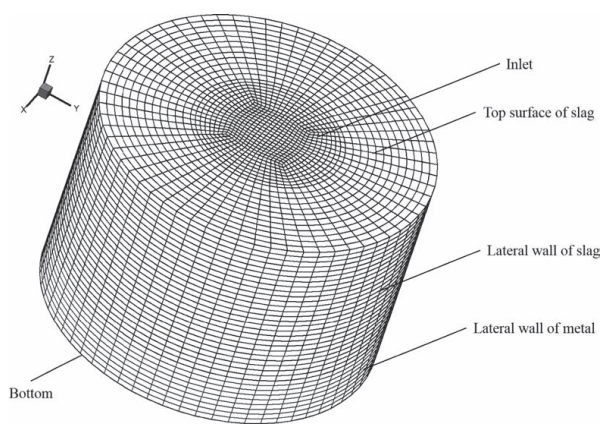

Fig. 2. Mesh at the initial state. 
It is typically approximately $260 \mathrm{CPU}$ hours for performing one case using 8 cores of $3.10 \mathrm{GHz}$.

\section{Experiment}

An experiment has been carried out using a mold with an open air atmosphere. The inner diameter, height and lateral wall thickness of the mold are $120 \mathrm{~mm}, 600 \mathrm{~mm}$ and 65 $\mathrm{mm}$, respectively. The root mean square and frequency of the AC are $1500 \mathrm{~A}$ and $50 \mathrm{~Hz}$. The consumable electrode is the AISI 201 stainless steel with a $55 \mathrm{~mm}$ diameter. The slag composition is calcium fluoride, 75 mass pct, and aluminum oxide, 25 mass pct. The slag layer thickness is constant at 60 $\mathrm{mm}$. The temperature in the slag region was measured every 3 minutes by the disposable W3Re/W25Re thermocouple. The Ni concentration in the final ingot, as shown in Fig. 3, was examined by the SPECTROLAB optical emission spectrometer.

\section{Results and Discussions}

\subsection{Electromagnetic Fields}

Figure 4 illustrates the simulated current density and Joule heating density fields at 950 second with the current of $1500 \mathrm{~A}$. The electric current flows downward from the inlet to the two sides. The maximal current density is found just near the periphery of the inlet and the minimum is located in the outer side of the top slag region. The skin effect is not observed, because the depth of skin effect is approximately $85 \mathrm{~mm}$ larger than the ingot radius. The Joule heating density is proportional to the current density, while inversely proportional to the electrical conductivity. Most Joule heating is generated in the slag due to the smaller electrical conductivity. Moreover, the distribution of the Joule effect is similar to that of the current density. Figure 5 displays the calculated Lorentz force and phase distribution. The inward Lorentz force generates a pinch effect. Thus, the metal moves toward the middle and forms a droplet.

\subsection{Thermal Behavior and Melt Flow}

Figure 6 represents the simulated temperature distribution, which is different from the one only induced by the

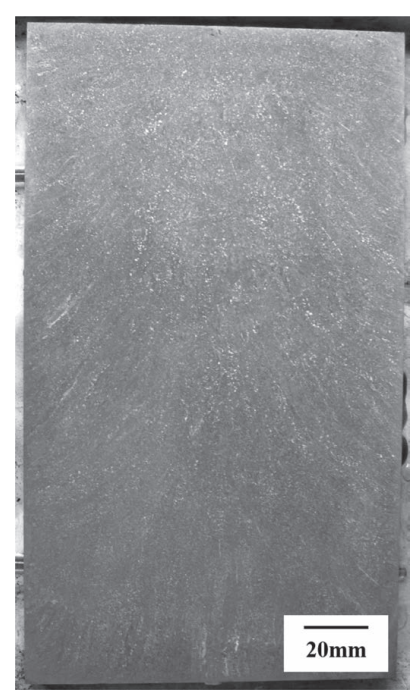

Fig. 3. Electroslag remelting ingot in the experiment.
Joule heating. ${ }^{21)}$ The highest temperature region is just at the same place with the maximal Joule effect mentioned above. The slag becomes colder from the top and a lower temperature region is observed at the outer edge of the bottom slag. With more heat, the slag is hotter than the metal. The colder metal droplet therefore is heated by the slag during its falling. Figure 7 shows the comparison of the temperature between the experimental measurements and simulated results. A reasonable agreement is obtained. The experimental measurements also indicate that the temperature of the upper slag is higher. In addition, the temperature increases with time, because the cooling at the bottom becomes weaker with the growing of the ingot.

Two pairs of vortices are found in the slag layer as shown in Fig. 8. The heat extracted by the cooling water results in a descent of the slag at the wall due to buoyancy. This

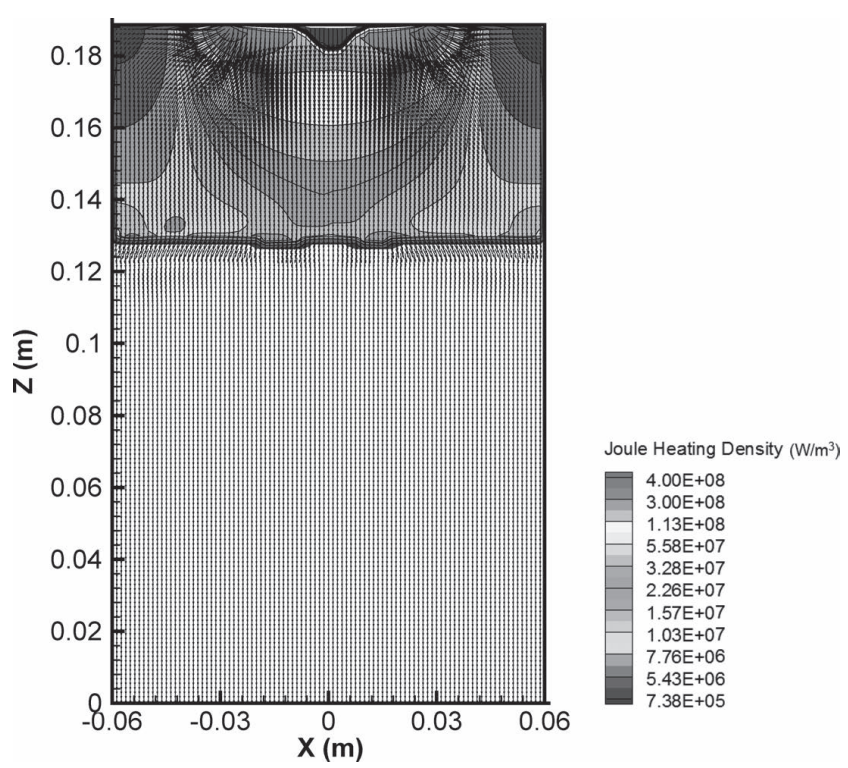

Fig. 4. Simulated current density and Joule heating density fields with a current of $1500 \mathrm{~A}$ at 950 second, and the maximal current density is $1.47 \times 10^{5} \mathrm{~A} / \mathrm{m}^{2}$.

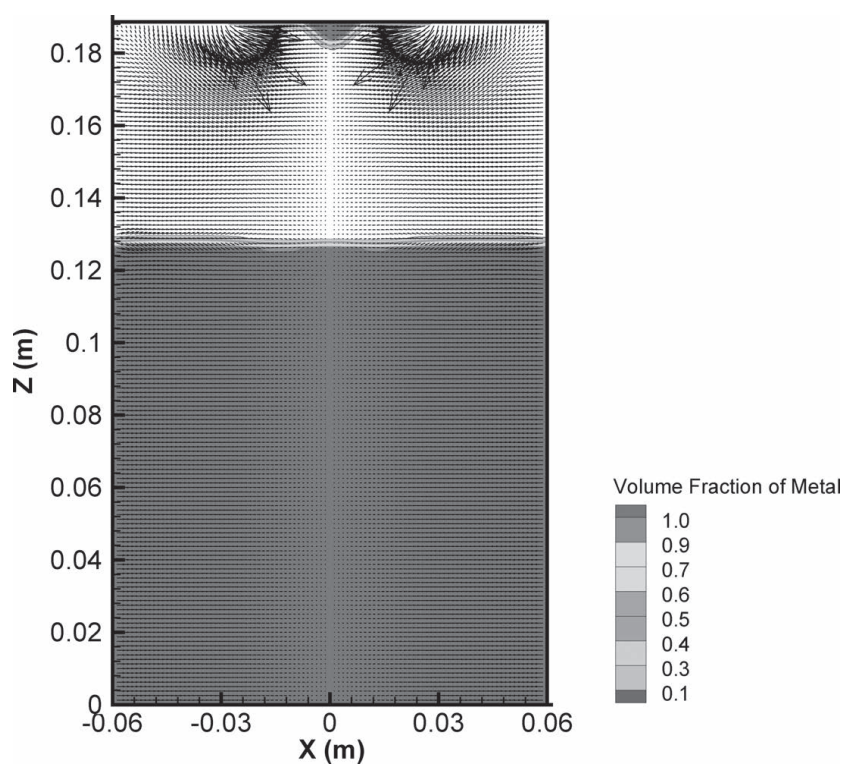

Fig. 5. Simulated phase distribution and Lorentz force field with a current of $1500 \mathrm{~A}$ at 950 second, and the maximal Lorentz force is $267 \mathrm{~N} / \mathrm{m}^{3}$. 


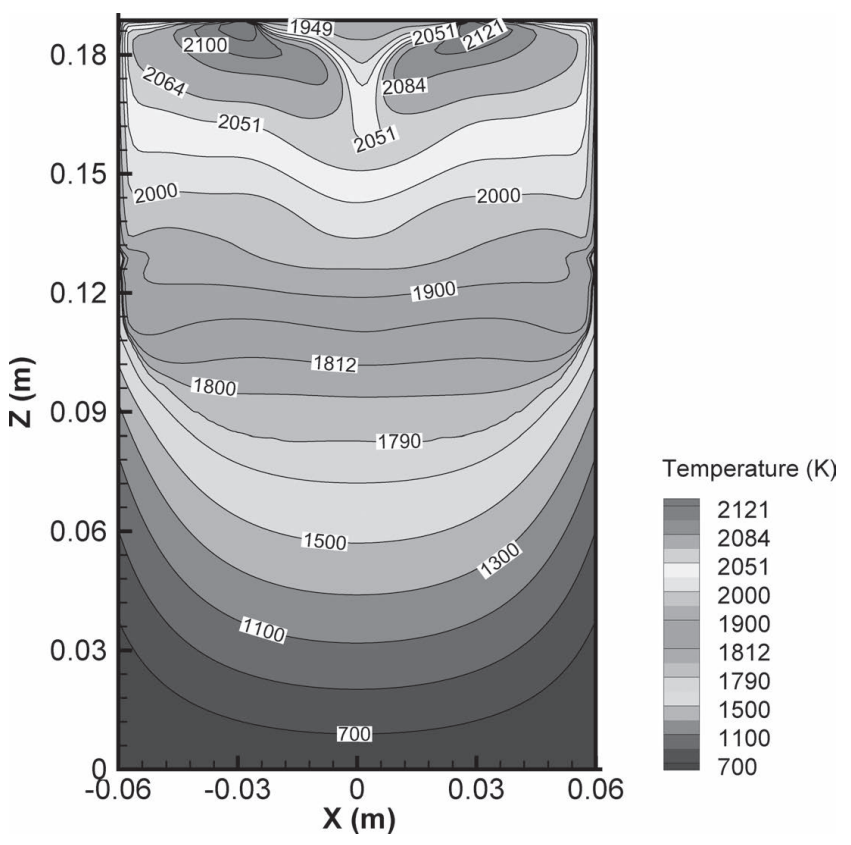

Fig. 6. Simulated temperature distribution with a current of 1500 A at 950 second.

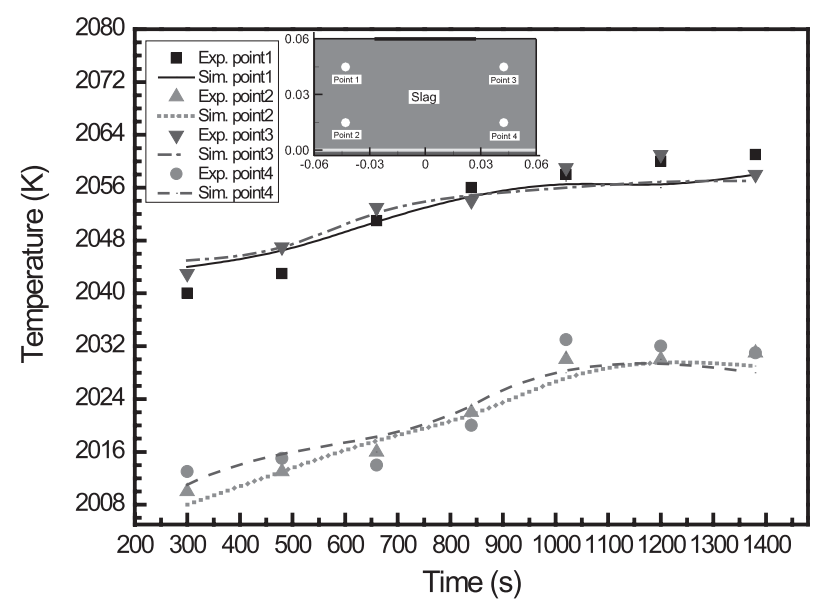

Fig. 7. Comparison of the temperature between the experiment and simulation.

causes a stable clockwise circulation, which can be seen on the right side of the figure. The downward flow at the lateral wall turns the corner to form a radial jet along the slag/metal interface. The strength of the jet diminishes as it moves inward and finally turns upward. At the center of the slag, a counterclockwise circulation is caused by the Lorentz force and the falling metal droplets. The heat extracted by the cooling water at the bottom and lateral wall, which drives the freezing of metal. A shallow metal pool therefore is formed. The flow in the metal pool is different from that in the slag. Due to the forced cooling, the thermal buoyancy dominates the flow pattern. The impact of the Lorentz force and solutal buoyancy are negligibly small. The clockwise cell in the pool results in the motion of heavy cold metal downward along the curved solidification front.

\subsection{Solute Distribution}

We will use Ni to trace the metal pool varying in our further work. The Ni distribution therefore is demonstrated in Fig. 9. The liquid composition in the mushy zone

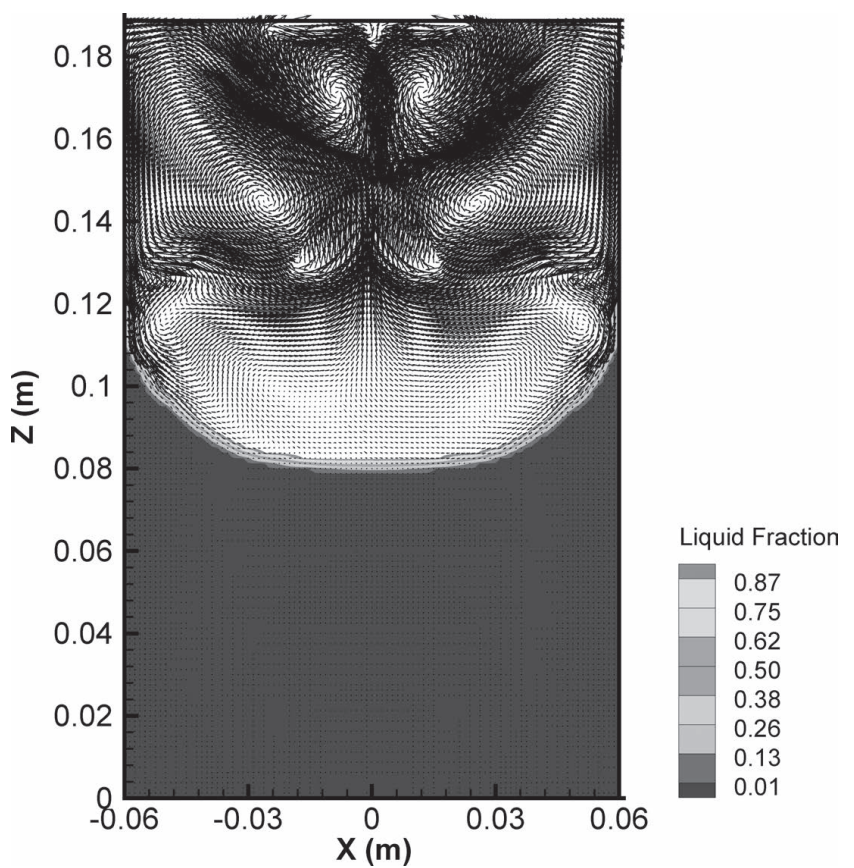

Fig. 8. Simulated velocity field and liquid fraction with a current of $1500 \mathrm{~A}$ at 950 second, and the maximal velocity is $0.06 \mathrm{~m} / \mathrm{s}$.

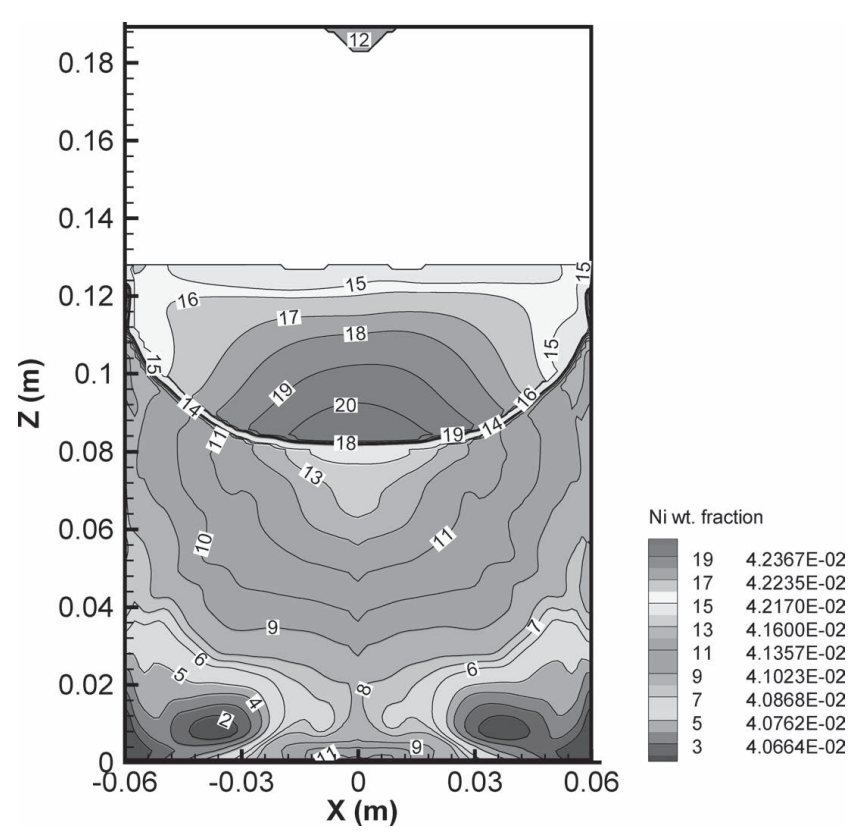

Fig. 9. Simulated Ni concentration distribution with a current of $1500 \mathrm{~A}$ at 950 second.

becomes enriched in Ni because of its partition ration. The interdendritic metal with a higher $\mathrm{Ni}$ is replaced by the $\mathrm{Ni}$ poor metal carried by the downward flow in the pool. The Ni composition therefore accumulates at the pool bottom, and the concentration increases with time. Additionally, the slow buoyancy driven flow drains the Ni composition from the bottom to the upper part of the pool, giving rise to a wider zone with the ingot growing. It can be seen that a lower concentration region at the both sides of the bottom, where the solidification occurs first and the $\mathrm{Ni}$ is depleted. The solute transport during the ESR process is dominated by the Lorentz force, thermal and solutal buoyancy forces. Two nondimensional criterions are defined to identify the influence of the three forces: ${ }^{18)}$ 


$$
M=\left|\frac{\vec{J} \times \vec{B}}{\vec{g} \beta_{T} \Delta T}\right| \text { and } N=\left|\frac{\beta_{c} \Delta c}{\beta_{T} \Delta T}\right|
$$

The $M$ and $N$ expresses the ratio of the Lorentz force to the thermal buoyancy and the solutal buoyancy to the thermal buoyancy, respectively. Figure 10 shows the $M$ and $N$ profiles along the ingot centerline. Both of them are less than one indicating that the thermal buoyancy dominates the species motion during the ESR process. Due to the increasing temperature gradient, the $M$ and $N$ decrease from top. In addition, a peak of $N$ is observed around the mushy zone where the Ni is enriched. Figure 11 represents the segregation indexes along the ingot centerline for various times. Both the experimental and simulation results show an oscillating segregation profile, negative at the bottom, rising to around the nominal concentration at approximately two-fifth of the ingot height and passing several times from negative to positive in the upward, until it reaches the maximal positive segregate and then slightly decreases. A reasonable agreement is obtained and the uncertainty about the thermal boundary conditions as well as the thermodynamics parameters is mainly responsible for the discrepancy. Thanks to rapid solidification, the $\mathrm{Ni}$ composition is immobilized before moving to the other place resulting in a lower segregation level in the ingot. Figure 12 displays the effect of the current on the macrosegregation. The macrosegregation patterns are similar. Yet, the segregation becomes severer

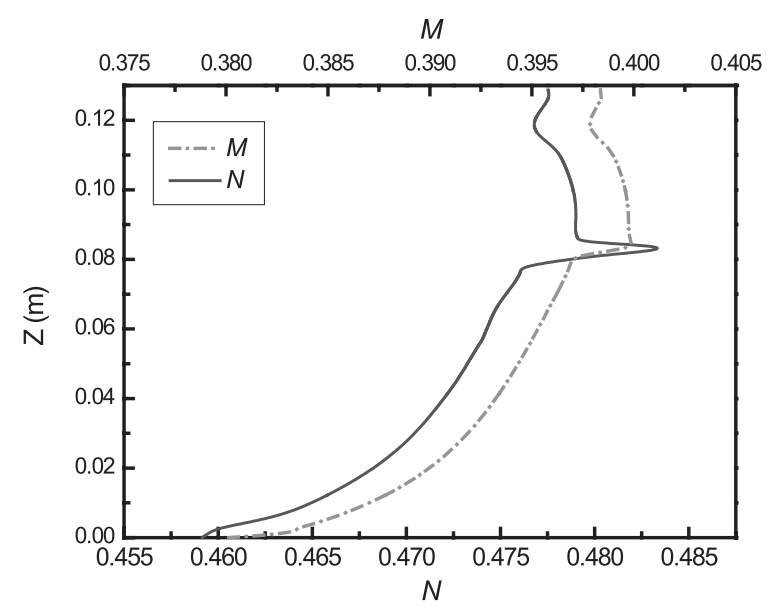

Fig. 10. Nondimensional criterion $M$ and $N$ profiles along the ingot centerline at 950 second.

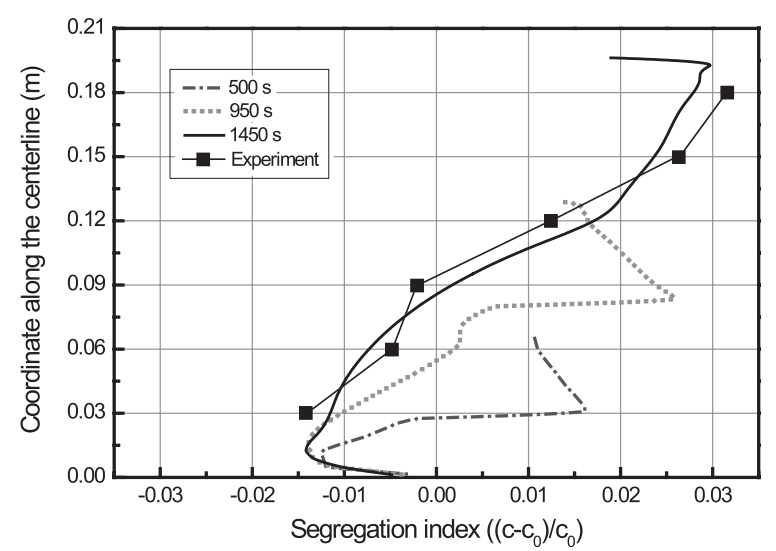

Fig. 11. Evolution of the segregation index along the ingot centerline with time. with the increasing current. More heat is generated resulting in a higher average temperature of the slag as shown in Fig. 13. Due to the constant cooling, the freezing rate decreases and the mushy zone becomes wider providing more opportunities for macrosegregation.

The most pregnant feature of our work is the investigation on the solute transport during the ESR process including the electromagnetism, two-phase flow and heat transfer. The species movement is dominated by the thermal buoyancy because of the strong cooling. In order to keep a lower segregation level, the cooling should be reinforced if we want to increase the current in the practice. The relationship between the current and cooling would be understood in our feature work.

\section{Conclusions}

A transient 3D comprehensive model is established to understand the solute transport during the ESR process. The electromagnetism, two-phase flow and heat transfer are taken into account. A reasonable agreement between the experimental and simulation results is obtained. The results indicate that the liquid composition in mushy zone becomes enriched in $\mathrm{Ni}$. The interdendritic metal with a higher $\mathrm{Ni}$ is replaced by the Ni poor metal carried by the downward flow in the pool. The Ni composition therefore accumulates at the pool bottom, and the concentration increases with time. The species movement is determined by the thermal buoyancy.

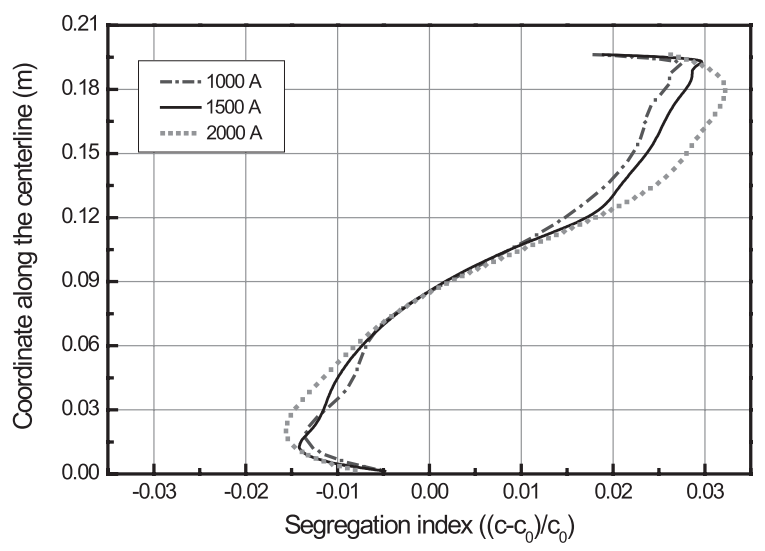

Fig. 12. Effect of the current on the segregation index along the ingot centerline.

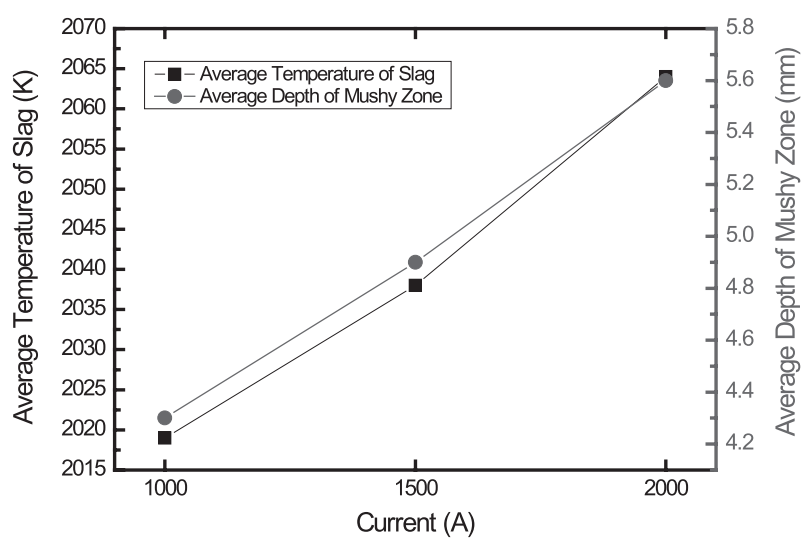

Fig. 13. Effect of the current on the average temperature of slag and average depth of mushy zone. 
The segregation profile shows a negative in the lower part and a positive in the upper part of the ingot. Thanks to the rapid solidification, the Ni composition is immobilized before moving to the other place resulting in a lower segregation level. The macrosegregation becomes severer with the increasing current. The maximal positive and negative segregation indexes increase from 0.02742 to 0.03226 and from -0.01346 to -0.01561 with the current ranging from 1000 A to $2000 \mathrm{~A}$. In order to reduce the macrosegregation, a good relationship between the current and cooling should be found in practice.

\section{Acknowledgements}

The authors' gratitude goes to National Natural Science Foundation of China [NO. 51210007] and Fundamental Research Funds of People's Republic of China for the Central Universities [N140206002].

\section{List of symbols}

$a_{p}:$ cell matrix coefficient

$\vec{B}$ : magnetic flux density (T)

$c_{i}$ : concentration of species $i$ (wt. \%)

$c_{\ell, i}, c_{s, i}:$ concentration in the liquid and solid phase of species $i$ (wt.\%)

$c_{0}: \quad$ initial concentration (wt. $\%$ )

$c_{p}: \quad$ specific heat at constant pressure $(\mathrm{J} /(\mathrm{kg} \cdot \mathrm{K}))$

$\Delta c$ : characteristic concentration difference for the solutal buoyancy (wt.\%)

$D_{\ell, i}, D_{s, i}: \quad$ diffusion coefficient in the liquid and solid phase of species $i\left(\mathrm{~m}^{2} / \mathrm{s}\right)$

$f_{\ell}, f_{s}: \quad$ liquid and solid fraction

$\vec{F}$ : Lorentz force $\left(\mathrm{N} / \mathrm{m}^{3}\right)$

$\vec{F}_{d}$ : turbulent damping force $\left(\mathrm{N} / \mathrm{m}^{3}\right)$

$\vec{F}_{s}: \quad$ solutal buoyancy $\left(\mathrm{N} / \mathrm{m}^{3}\right)$

$\vec{F}_{t}: \quad$ thermal buoyancy $\left(\mathrm{N} / \mathrm{m}^{3}\right)$

$\vec{g}$ : gravity $\left(\mathrm{m} / \mathrm{s}^{2}\right)$

$h$ : $\quad$ sensible enthalpy $(\mathrm{J} / \mathrm{kg})$

$h_{\text {ref: }}$ reference sensible enthalpy $(\mathrm{J} / \mathrm{kg})$

$\vec{H}: \quad$ magnetic field intensity $(\mathrm{A} / \mathrm{m})$

$\hat{H}:$ complex amplitude $(\mathrm{A} / \mathrm{m})$

$H$ : enthalpy $(\mathrm{J} / \mathrm{kg})$

I: root mean square of the current (A)

$\vec{J}: \quad$ current density $\left(\mathrm{A} / \mathrm{m}^{2}\right)$

$k_{i}$ : partition coefficient of species $i$

$k_{\text {eff }}: \quad$ effective thermal conductivity $(\mathrm{W} /(\mathrm{m} \cdot \mathrm{K}))$

$L: \quad$ latent heat $(\mathrm{J} / \mathrm{kg})$

$m_{i}$ : liquidus slope of species $i(\mathrm{~K} / \mathrm{wt} . \%)$

$M$ : the ratio of the Lorentz force to the thermal buoyancy

$N$ : the ratio of the solutal buoyancy to the thermal buoyancy

$p: \quad$ pressure $(\mathrm{Pa})$

$Q$ : Joule heating $\left(\mathrm{W} / \mathrm{m}^{3}\right)$

$r$ : $\operatorname{radius}(\mathrm{m})$

$S c_{t}$ : turbulent Schmidt number

$S_{s, \text { con }}$ : $\quad$ source term represents the convection diffusion

$S_{S, d i f}$ : $\quad$ source term represents the molecular diffusion

$t$ : time (s)

$\Delta t: \quad$ time step (s)
$T: \quad$ temperature $(\mathrm{K})$

$T^{*}: \quad$ liquid/solid interface temperature $(\mathrm{K})$

$T_{\ell}$ : liquidus temperature $(\mathrm{K})$

$T_{\text {pure }}$ : $\quad$ melting point of the pure iron $(\mathrm{K})$

$T_{\text {ref: }}$ reference temperature $(\mathrm{K})$

$T_{s}: \quad$ solidus temperature $(\mathrm{K})$

$\Delta T$ : characteristic temperature difference for the thermal buoyancy $(\mathrm{K})$

$V_{c}: \quad$ cell volume $\left(\mathrm{m}^{3}\right)$

$\vec{v}: \quad$ velocity $(\mathrm{m} / \mathrm{s})$

$\vec{v}_{s}: \quad$ velocity of solid phase $(\mathrm{m} / \mathrm{s})$

Greek symbols

$\beta_{c}$ : solutal expansion coefficient (wt. $\%^{-1}$ )

$\beta_{T}$ : thermal expansion coefficient $\left(\mathrm{K}^{-1}\right)$

$\eta$ : magnetic diffusivity $\left(\Omega \cdot \mathrm{m}^{2} / \mathrm{H}\right)$

$\lambda$ : relaxation factor in Eq. (9)

$\mu_{\text {eff: }} \quad$ effective viscosity $(\mathrm{Pa} \cdot \mathrm{s})$

$\mu_{t}$ : turbulent viscosity $(\mathrm{Pa} \cdot \mathrm{s})$

$\rho:$ density $\left(\mathrm{kg} / \mathrm{m}^{3}\right)$

$\omega: \quad$ angular frequency $(\mathrm{Hz})$

\section{REFERENCES}

1) B. Hernandez-Morales and A. Mitchell: Ironmaking Steelmaking, 26 (1999), 423.

2) A. Ludwig, A. Kharicha and M. Wu: Metall. Mater. Trans. B, 45B (2014), 36.

3) A. Mitchell: Mater. Sci. Eng. A, 413 (2005), 10.

4) J. Li, M. Wu, A. Ludwig and A. Kharicha: Int. J. Heat Mass Tran., 72 (2014), 668.

5) H. Combeau, M. Založnik, S. Hans and P. E. Richy: Metall. Mater. Trans. B, 40B (2009), 289.

6) J. P. Gu and C. Beckermann: Metall. Mater. Trans. A, 30A (1999), 1357.

7) S. Kou, D. R. Poirier and M. C. Flemings: Metall. Trans. B, 9B (1978), 711.

8) S. D. Ridder, F. C. Reyes, S. Chakravorty, R. Mehrabian, J. D. Nauman, J. H. Chen and H. J. Klein: Metall. Trans. B, 9B (1978), 415.

9) K. Fezi, J. Yanke and M. J. M. Krane: Proc. 2013 Int. Symp. on Liquid Metal Processing \& Casting, TMS, Warrendale, PA, (2013), 151.

10) K. M. Kelkar, S. V. Patankar and A. Mitchell: Proc. 2005 Int. Symp. on Liquid Metal Processing and Casting, TMS, Warrendale, PA, (2005), 137.

11) A. Kharicha, A. Mackenbrock, A. Ludwig, W. Schützenhöfer, V. Maronnier, M. Wu and O. Köser: Proc. 2007 Int. Symp. on Liquid Metal Processing and Casting, TMS, Warrendale, PA, (2007), 107.

12) S. A. Cefalu, K. J. Vanevery and M. J. M. Krane: Multiphase Phenomena and CFD Modeling and Simulation in Materials Processes, TMS, Warrendale, PA, (2004), 279.

13) V. Weber, A. Jardy, B. Dussoubs, D. Ablitzer, S. Rybéron, V. Schmitt, S. Hans and H. Poisson: Metall. Mater. Trans. B, 42B (2009), 271.

14) K. Pericleous, G. Djambazov, M. Ward, L. Yuan and P. D. Lee: Metall. Mater. Trans. A, 44A (2013), 5365.

15) M. C. Schneider and C. Beckermann: Metall. Mater. Trans. A, 26A (1995), 2372.

16) M. Choudhary and J. Szekely: Metall. Mater. Trans. B, 11B (1980), 439.

17) A. H. Dilawari and J. Szekely: Metall. Mater. Trans. B, 8B (1977), 227.

18) M. Založnik and H. Combeau: Int. J. Therm. Sci., 49 (2010), 1500.

19) Q. Wang, Z. He, B. K. Li and F. Tsukihashi: Metall. Mater. Trans. $B, 45 B$ (2014), 2425

20) M. Revil-Baudard, A. Jardy, H. Combeau, F. Leclerc and V. Rebeyrolle: Metall. Mater. Trans. B, 45B (2014), 51.

21) B. K. Li, F. Wang and F. Tsukihashi: ISIJ Int., 52 (2012), 1289.

22) B. K. Li, B. Wang and F. Tsukihashi: Metall. Mater. Trans. B, 45B (2014), 1122.

23) V. R. Voller and A. D. Brent: Int. J. Heat Mass Tran., 32 (1989), 1719.

24) J. Ni and F. P. Incropera: Int. J. Heat Mass Tran., 38 (1995), 1271.

25) G. M. Poole, M. Heyen, L. Nastac and N. El-kaddah: Metall. Mater. Trans. B, 45B (2014), 1834. 